\title{
Landscape fragmentation and pollinator movement within agricultural environments: a modelling framework for exploring foraging and movement ecology
}

Pollinator decline has been linked to landscape change, through both habitat fragmentation and the loss of habitat suitable for the pollinators to live within. One method for exploring why landscape change should affect pollinator populations is to combine individual-level behavioural ecological techniques with larger-scale landscape ecology. A modelling framework is described that uses spatially-explicit individual-based models to explore the effects of individual behavioural rules within a landscape. The technique described gives a simple method for exploring the effects of the removal of wild corridors, and the creation of wild set-aside fields: interventions that are common to many national agricultural policies. The effects of these manipulations on central-place nesting pollinators are varied, and depend upon the behavioural rules that the pollinators are using to move through the environment. The value of this modelling framework is discussed, and future directions for exploration are identified. 
1 Landscape fragmentation and pollinator movement within agricultural

2 environments: a modelling framework for exploring foraging and movement

3 ecology

4

5

6 Sean A. Rands

7

8 School of Biological Sciences, University of Bristol, Bristol, United Kingdom

9

10 CORRESPONDENCE ADDRESS: School of Biological Sciences, Woodland Road,

11 Bristol BS8 1UG, United Kingdom

12 TELEPHONE: $\quad+44(0) 1179289177$

13 EMAIL: sean.rands@bristol.ac.uk

14

15

16

17

18

19 


\section{INTRODUCTION}

(1)

Pollinators provide vital ecosystem services in both wild habitats and the agricultural landscape, where they contribute enormous economic value to the production of crop species (Morandin \& Winston, 2006; Gallai et al., 2009). In addition to managed pollination by honeybees, it is being increasingly acknowledged that unmanaged wild species may be providing a vast amount of pollination within the managed environment (Winfree et al., 2007; Holzschuh, Dudenhöffer \& Tscharntke, 2012; Garibaldi et al., 2013). However, it is acknowledged that many species of pollinator are in decline (Biesmeijer et al., 2006; Goulson, Lye \& Darvill, 2008). Considerable scientific effort is currently being devoted to understanding this decline (Potts et al., 2010), in an effort to identify strategies for both arresting and reversing it (Brown \& Paxton, 2009; Winfree, 2010).

Land-use change is frequently considered to be a major contributor to pollinator decline (Potts et al., 2010), through both habitat fragmentation (but see Hadley \& Betts, 2012) and the loss of habitat suitable for pollinators (Fischer \& Lindenmayer, 2007). Many regional agricultural management schemes aim to counteract this, through the creation of wild habitat within the agricultural landscape. This is presumed to be beneficial to pollinators, through providing either wild refuge areas, or providing corridors to facilitate movement (e.g. Batáry et al., 2011; Ernoult et al., in press). These landscape manipulations may therefore be beneficial to enhancing pollination within the landscape. Patches of wild refuge and set-aside land have been demonstrated to enhance biodiversity with the agricultural environment (van Buskirk \& Willi, 2004; Orłowski, 2010; Carvalheiro et al., 2011; Norfolk et al., 2013). 
45 However, the value of corridors is debatable: corridors can both aid pollinators to move through the environment (such as through giving visual signposting or an obstruction-free route) and hinder their movement (such as by providing physical barriers) through the environment (Collinge, 2000; Fried, Levey \& Hogsette, 2005; Davies \& Pullin, 2007; Beier \& Noss, 2008; Öckinger \& Smith, 2008), and may even be harmful if they allow the spread of invasive species (Procheş et al., 2005). Even if a corridor is demonstrated to be a useful feature to add to the environment, the corridor on its own may not provide extra value to the landscape, as the composition of the landscape adjacent to the corridors may also contribute to how well they function (Baum et al., 2004).

Because the evidence is relatively mixed for the value of these mitigation strategies, we therefore need to better understand the effects that these different environmental manipulations have on the pollinators that live within them. As well as observational studies comparing existing manipulations, we can conduct experimental manipulations (Jenerette \& Shen, 2012). We can also investigate the biology and effects of the manipulations using theoretical models, which allow us to explore many different scenarios without conducting expensive and time-consuming field trials.

Careful model formulation allows us to identify aspects of the biology of the pollinating species that may impact on how they interact with the environment. In particular, as urged by Lima \& Zollner (1996), we can tie concepts from behavioural ecology with landscape ecology, to better inform how organisms are interacting with the habitat in which they live. 
69 Techniques such as resource-selection function models use characteristics of the

70 environment and the physiology and potential nesting locations of pollinating species

71 of interest, and have been used to identify the likely site of foraging (Forester, Im \&

72 Rathouz, 2009; Lonsdorf et al., 2009; Henry et al., 2012). However, further realism

73 can come if we tie spatially-explicit landscapes with well-developed concepts from

74 behavioural ecology. Individual-based models of movement within a landscape allow

75 us to model the movement path of individuals, based on their internal state (e.g.

76 physiological requirements) and their capacity to perceive and move through the

77 environment, and can accommodate external factors such as structure of the

78 environment (Nathan et al., 2008; Martin et al., 2013). Spatially-explicit individual-

79 based models (McLane et al., 2011) have been used to explore diverse questions in

80 behavioural ecology (e.g. Rands et al., 2004; 2006; Rands, 2012). We would expect

81 that the foraging decisions and movements of pollinators will be affected by local

82 resource availability, resource quality, and the ease of locating resources and moving

83 through the environment. In turn, these can be tied to the physical composition of the

84 landscape. All of these factors will be changing dynamically, and will be subject to

85 weather, interference from other foragers, and anthropogenic change within the

86 environment. Spatially-explicit individual-based techniques are therefore ideal for

87 exploring the effects of habitat fragmentation and change on the behaviour of

88 pollinators nesting within the environment, as they allow us to consider the effects of

89 behavioural rules within a spatially complex environment.

90

91 Here, I develop a framework for considering pollinator movement within the

92 environment, using a spatially-explicit individual-based model of the behaviour of a

93 central-place forager that is nesting within its environment. I build on the spatially- 
explicit models presented by Rands \& Whitney (2010; 2011), which simply

considered the proportion of resources available within a maximum foraging range to consider how landscape manipulation can affect their movement. through the environment. Considering behavioural movement rules is important, but this consideration is frequently missing from landscape ecology models (Bélisle, 2005). In this framework, I consider a landscape that can be seen as a mixture of foraging opportunities, rather than as a series of connected patches. The structure of the landscape will affect how a pollinator experiences foraging sites, and it is possible that specific behavioural rules will mean that the pollinator is less likely to reach some areas of the landscape if their movement rules do not allow them to reach that area.

Understanding these local effects is important, because many important pollinators do not travel far (Zurbuchen et al., 2009), and are constrained to remain near their nest. I develop a framework for an agricultural field system where fields are surrounded by strips of wild land, and consider how pollinators following some simple behavioural rules might move through this environment. I then explore whether landscape manipulations (removing corridors, and adding 'set-aside' wild land) have effects upon the amount of movement and the behavioural choices made by foraging pollinators within the landscape. I also consider the special case for specialist pollinators that are unable to forage outside the wild regions of the environment, and

\section{METHODS}


120 The field-based landscape within these simulations is initially generated as a grid-

121 based Voronoi tessellation, described in detail in Rands \& Whitney (2011), where an

122 initial grid of square cells is seeded with a given number of field seeds. Fields are then

123 calculated by allocating individual cells in the grid to the field characterised by the

124 seed closest to that cell. Field edges, considered as 'wild' land, are cells that have at

125 least one immediate neighbour that belongs to a different field, following Rands \&

126 Whitney (2011). Any part of the environment that is not a field edge is considered to

127 be a field, and contains cultivated land (considered as monoculture, following Rands

$128 \&$ Whitney, 2010, 2011). This means that all the fields of cultivated land are separated

129 from each other by field edges, which could be considered as hedgerows, or wild

130 strips, or any other form of non-cultivated component of the landscape. The nests of

131 the pollinators (I am assuming these to be a central-place foraging pollinator that

132 returns to a nest, such as solitary bee or bumblebee) are assumed to be located within

133 the field edges, as the cultivated component of the landscape may be too disturbed to

134 allow a nest to survive. The $(x, y)$ coordinates of the nest are taken to be the initial

135 starting position of a foraging pollinator.

137 The state of an individual foraging pollinator is defined by its position (in $(x, y)$

138 coordinates) and its current direction of travel, which is equal to the direction it

139 moved in from the previous to current square. An individual can move in any of the

140 four directions available by moving to a grid square sharing a side with the current

141 position. The neighbouring square that would be entered if the pollinator continued in

142 its current direction of travel is defined as the 'forward' square, and the pollinator is

143 defined as travelling 'forward' into it. The neighbouring square if the pollinator 
144 rotated $90^{\circ}$ clockwise from its current direction of travel is the 'right' square (and the

145 pollinator travels 'right'). Similarly, the squares that would be entered if the pollinator

146 rotated $180^{\circ}$ and $270^{\circ}$ clockwise are the 'backwards' and 'left' squares respectively

147 (with the pollinator travelling 'backwards' and 'left').

148

149 I assume movement follows a correlated random walk. If we initially ignore the

150 contents of the grid, the unadjusted probabilities that the pollinator moves either

151 forwards or backwards are $p_{F}$ and $p_{B}$. I assume that the pollinator's unadjusted

152 tendency to deviate from going forwards is symmetrical, so the chances of moving to

153 the squares on the left or right sides have equal probabilities, both $p_{S}$, where $p_{F}+p_{B}+$

$1542 p_{\mathrm{S}}=1$. However, the probabilities that the pollinator moves into neighbouring

155 squares is also influenced by the pollinator's tendency to switch between habitat

156 types. I assume that the content of its current location is $c_{\text {current }}$, and the contents of the

157 neighbouring squares forward, backward, left and right of the current square are $c_{F}$,

$158 c_{B}, c_{L}$ and $c_{R}$ respectively. I then assume an adjusted preference $m_{i}$ for entering square

$159 i$ where switching habitat type incurs a reduction $r$, such that

160

161

$$
m_{i}= \begin{cases}p_{i} & \text { if } c_{i}=c_{\text {current }} \\ r p_{i} & \text { if } c_{i} \neq c_{\text {current }}\end{cases}
$$

163 The actual probability $a_{i}$ that an individual moves in direction $i$ is calculated as

$164 a_{i}=m_{i} /\left(m_{F}+m_{B}+m_{L}+m_{R}\right)$. Using these four probabilities of movement, the

165 pollinator then randomly picks its direction of movement for the period. 
167 All simulations were written in $\mathrm{C}++$ (available in Supplemental Information 1) and

168 run using XCode 4 and 5 (Apple Inc., Cupertino). Random numbers were generated

169 within the simulations using a Mersenne twister algorithm (Matsumoto \& Nishimura, 170 1998).

171

172 MODEL 1: Effects of movement choice

173

1741000 environments were independently generated. Each environment was $1000 \times 1000$

175 uniform squares with an edge length of one grid unit, and had a random number of

176 fields (chosen from the range [101, 200]) seeded within the environment using

177 randomly chosen coordinates. Voronoi-tessellated field boundaries were then created

178 using the algorithm described in Rands \& Whitney (2011), assuming that field edges

179 were of a single thickness: this meant that every cell in a hedgerow was connected via

180 at least one of its edges to another hedgerow cell (see Figure 1 for an example).

181

182 For each environment, a switching reduction $r$ was randomly selected from $(0,1)$, and

183 a random constant $v$ was randomly selected from $(0,1)$. Single model runs were then

184 calculated using the environment field description, each with systematic alteration of

$185 p_{F}$ where $p_{F} \in\{0.25,0.375, \ldots, 0.875\}, p_{S}=\left(\left(1-p_{F}\right) / 3\right)+\left(v\left(1-p_{F}\right) / 6\right)$, and $p_{B}=1-p_{F}-$

$1862 p_{S}$. In each model run, a pollinator that started at the nest was followed for 1000

187 timesteps. Over these timesteps, I recorded the maximum distance the pollinator

188 travelled from the nest, the number of times it switched between habitat types, and the

189 proportion of time it spent in the hedgerow habitat type. These calculations were

190 repeated over all of the 1000 environment types generated.

191 
194 The modelling of the environment was similar to Model 1. However, rather than

195 systematically altering $p_{F}, r$ was systematically altered, where $r \in\left\{(2 / 3)^{0},(2 / 3)^{1}, \ldots\right.$,

$\left.196(2 / 3)^{13}\right\}$. For each environment, $p_{F}$ was randomly chosen from $(0.25,1), p_{S}=((1-$ $\left.\left.p_{F}\right) / 3\right)+\left(v\left(1-p_{F}\right) / 6\right)$ where $v$ was randomly chosen from $(0,1)$, and $p_{B}=1-p_{F}-2 p_{S}$.

\section{MODEL 3: Effects of including set-asides}

201 The modelling of the environment was similar to Model 2, but within each environment, $r$ was randomly chosen value within $(0,1)$. For each environment, a basal landscape of fields with hedgerows was created as described in Model 1, and pollinator movement statistics were calculated. Five of the fields were then randomly selected as set-asides, and all the squares within these set-aside fields were filled with wild hedgerow vegetation (see Figure 1 for a sketch of how this was implemented), and pollinator movement statistics were calculated. Five more fields were then filled as set-asides (giving the environment ten set-asides in total), with movement statistics calculated. This addition of five set-aside fields with movement calculations was

210 repeated until fifty of the original fields had been filled as set-asides.

212 Factorial sensitivity analysis (Hamby, 1994) was also conducted, by systematically 213 increasing the number of set-asides over the range $(0,5, \ldots, 50)$ whilst varying $a) p_{F}$ 214 over $(0.1,0.2, \ldots, 0.9) ; b) p_{S}$ over $(0,0.05, \ldots, 0.45)$ whilst setting $p_{F}=\left(1-2 p_{S}\right) \times$

215 (random value from range [0,1]); and $c$ ) $r$ over $(0,0.1, \ldots, 0.9) .1000$ different 216 randomised sets of the parameters that were not being investigated within each set 
were generated as described in the main Methods section. For each of these parameter sets, one individual pollinator was moved through the generated environment for all possible combinations of the pair of parameters that were being investigated.

MODEL 3a: Effects of including set-asides when pollinators do not change

\section{habitat}

This model was identical to Model 3, but $r=0$, meaning that the pollinators did not swap habitats, and therefore did not move into fields that were not set-aside. Only the maximum geometric distance from the nest was calculated.

\section{MODEL 4: Effects of removing hedgerows}

The modelling of the environment and calculation of movement was calculated in a

231 similar way to Model 3. However, rather than filling fields as set-asides, the basal

232 environments were altered by cumulatively removing the hedgerows between fields.

233 An individual hedge was considered to be the grid squares designated as hedgerow

234 that fall between two identifiable field seeds, similar to a vertex in a Voronoi

235 tesselation. Movement statistics were calculated for the basal environment and then

236 after every four consecutive hedgerow removals, meaning that movement statistics

237 were calculated after $0,4, \ldots, 40$ hedges were removed (see Figure 2 for a sketch of

238 how this was implemented). Factorial sensitivity analysis (Hamby, 1994) for the

239 effects of $p_{F}, p_{S}$ and $r$ on Model 4 were conducted in a similar way to those described

240 above for Model 3, but by systematically increasing the number of hedgerows

241 removed over the range $(0,4, \ldots, 40)$ rather than the number of set-asides present. 
243 MODEL 4a: Effects of removing hedgerows when pollinators do not change

\section{4 habitat}

246 This model was identical to Model 4, but $r=0$, meaning that the pollinators did not 247 swap habitats, and therefore could become more limited in their movements as the 248 removal of hedgerows fragmented the corridors within the landscape. Only the 249 maximum geometric distance from the nest was calculated.

Statistical analysis

Using lme4 0.999999-0 (Bates, Maechler \& Bolker, 2012) in R 2.15.1 (R

Development Core Team, 2012), the three measures of movement (maximum distance modelled separately as linear mixed models against the variable being systematically changed in each model, with simulation run (with a specific fixed set of randomly generated environmental parameters) considered to be a random factor. Models

259 including the systematically altered variable were compared with the equivalent null

260 models missing the variable, and these were compared using a likelihood ratio test. If

261 this test was significant, post-hoc pairwise Tukey tests were conducted using

262 multcomp 1.2-12 (Hothorn, Bretz \& Westfal, 2012) to explore the shape of the 263 relationship. 
MODEL 1: Effects of movement choice

As would be expected, increasing the likelihood of choosing to move forward during

271 a period $\left(p_{F}\right)$ increased the maximum distance away from the nest that an individual reached (Figure $3 a$, Table 1). Although there were differences in the number of times the forager switched environment (Table 1), this trend had no obvious pattern (Figure $3 b$, Supplemental Information 10). There was a tendency for the proportion of time spent in the wild environment to reduce as the probability of moving forwards increased (Table 1), but this reduction was small (Figure 3c).

MODEL 2: Effects of altering the probability of switching foraging habitat

Increasing the probability of switching foraging habitat during a period $(r)$ led to a

281 small increase in the maximum distance travelled away from the nest (Figure $4 a$,

282 Table 1). As would be expected, increasing the probability of switching led to an 283 increase in number of switches (Figure $4 b$, Table 1). There was a reduction in the time 284 spent in 'wild' habitat (Figure 4c, Table 1): foragers were much more likely to spend 285 time in the 'wild' habitat if they were not likely to switch habitat, presumably because 286 they began their foraging trip within the 'wild' habitat.

MODEL 3: Effects of including set-asides

290 Increasing the number of set-aside fields within the habitat had little effect upon the 291 maximum distance foragers travelled away from their nest (Figure 5a, Table 1), but 
292 led to a decrease in the time they switched between habitats (Figure 5b, Table 1) and

293 an increase in the time they spent within the 'wild' habitat (Figure 5c, Table 1).

294 Sensitivity analyses are presented in Supplemental Information 2, 3, 4 and 5: trends

295 for two parameters combined follow what is expected when each of the parameters

296 are considered individually, are there appear to be no unexpected interactions between 297 parameters.

MODEL 3a: Effects of including set-asides when pollinators do not change

\section{habitat}

301

302 Increasing the number of set-aside fields within the habitat led to a slight increase in

303 the distance travelled from the nest when the foragers were constrained to remain

304 within the 'wild' habitat (Figure $5 d$, Table 1).

305

306 MODEL 4: Effects of removing hedgerows

307

308 Although there was an effect of increasing the number of hedgerows removed from

309 the environment upon the maximum distance a forager travelled away from its nest

310 (Table 1), this effect did not yield a easily describable trend (Figure 6a, Supplemental

311 Information 10). Increasing the number of hedgerows removed led to a slight decrease

312 in the number of times the forager changed habitat (Figure 6b, Table 1) and the time

313 spent in the 'wild' habitat (Figure $6 c$, Table 1). Sensitivity analyses are presented in

314 Supplemental Information 6, 7, 8, and 9: trends for two parameters combined follow

315 what is expected when each of the parameters are considered individually, are there

316 appear to be no unexpected interactions between parameters. 
318 MODEL 4a: Effects of removing hedgerows when pollinators do not change

\section{9 habitat}

321 As for Model 4, although there was an effect of removing hedgerows on the

322 maximum distance a forager moved when it was constrained to stay within the 'wild'

323 habitat (Table 1), the trend seen was not a simple increase or decrease (Figure $6 d$,

324 Supplemental Information 10).

\section{DISCUSSION}

\section{Movement Rules}

331 Movement rules are important in determining where and how far pollinators travel. In

332 the first two models, I demonstrate this using two simple behavioural rules based on 333 simple random walks and habitat preferences (where the habitat preference results 334 echo those described by Rands \& Whitney, 2010). Many other behavioural rules for 335 moving through landscapes are possible (Getz \& Saltz, 2008), and understanding the 336 movement process itself is arguably a key consideration in formulating realistic and 337 useful models of animal movement within the environment (Schick et al., 2008).

338 However, I chose to use naïve directed random walks in this example for the sake of 339 keeping this initial framework simple. 
341 More realistic rules are likely to involve some degree of state-dependence, taking into

342 account dynamic changes in both the external environment and the internal state of

343 the moving individual (Rands et al., 2004; 2006; Nathan et al., 2008; Martin et al.,

344 2013) Martin et al., 2013). Taking a behavioural ecology approach, ideally we want to

345 identify a behavioural rule-set that optimises the fitness of an individual, based on

346 how its actions are influenced by internal state and the environment (Houston \&

347 McNamara, 1999). Both of these may change dynamically in response to the actions

348 conducted. Furthermore, we may also need to consider how the movement rules are

349 constrained by the behavioural mechanisms that can be used (McNamara \& Houston,

350 2009), which may not be able to exactly enact the exact optimal behaviour identified

351 (Rands, 2011). The modelling framework discussed here uses a toy example of the

352 movement behaviour used by individuals, but could be refined to consider an optimal

353 rule-set (or indeed could be used to identify those rule-sets which allow individuals to

354 respond appropriately to their current environment, such as shown by Morrell, Ruxton

$355 \&$ James, (2011). If the framework was being used to identify optimal rules, it would

356 be essential to identify an appropriate currency to optimise: see Rands \& Whitney

357 (2008) and Charlton \& Houston (2010) for discussion of which currencies may be

358 appropriate to central-place nesting pollinators.

360 To fully understand movement through the environment, we need to consider the

361 behavioural rules shown by individuals at the small, local scale (such as within

362 patches of flowers, where pollinators are choosing how they move between individual

363 flowers) and at the larger landscape scale: the framework I present here is more suited

364 to the latter of these. Much empirical and theoretical work has been devoted to

365 understanding finer-scale local rules, and many experiments picking apart choice 
behaviour have been done within confined apparatus that may be constraining the rule set open to the pollinator. Many central-place foragers are known to trapline, where they form and then maintain an established route of visitation during a foraging bout,

369 which may act to optimise the amount of resource they are returning to their nest

370 (Lihoreau et al., 2012). This has been demonstrated to both enhance the resources gained by the forager (Ohashi \& Thomson, 2009; Reynolds, Lihoreau \& Chittka, 2013), and possibly enhance the pollen flow between the plants visited (Ohashi \& Thomson, 2009). Memory and the requirement for environmental sampling should therefore also be considered within a realistic model of pollinator movement.

\section{The effects of landscape manipulation}

The framework presented gives a clean and simple method for exploring the effects of

380 landscape manipulation on the movement behaviour of pollinators. Increasing the 381 number of set-asides gave an increase in the amount of time spent in 'wild' habitat, 382 and a decrease in the amount of habitat switching (Model 3). This is unsurprising, 383 given that the amount of wild land in the immediate environment of the pollinator was 384 being increased, with the accompanying increase in the average number of wild 385 squares neighbouring a focal wild square. The effects of removing wild strips was 386 slight (Model 4), and had little effect upon the maximum distance travelled from the 387 nest.

389 Therefore, although the modelling technique was relatively simple, it is likely that the 390 movement rules used were too simple to accurately reflect what might be happening 
391 when pollinators are responding to anthropogenic change. Given more suitable

392 behavioural rules, the framework could be used to investigate the effects of field

393 shape, as it has been demonstrated that field shape is a factor that can affect the

394 presence of invertebrates in an agricultural environment (Yaacobi, Ziv \& Rosenzweig,

395 2007; Orrock et al., 2011). It would be relatively easy to manipulate simplified raster-

396 based landscape information (such as the UK mapping data used by Rands \&

397 Whitney, 2011) to explore the effects of landscape manipulation within a specific

398 agricultural environment.

399

400

401 Landscape manipulation and specialist pollinators

402

403 I also considered the effects of environmental manipulations on the travelling distance

404 of specialist pollinators that were unable to move into the cultivated landscape

405 (Models 3a and 4a). Including set-aside wild fields slightly increased the distance

406 travelled, but the removal of corridors had subtle and mixed effects. Arguably, the

407 rules used in this model were too simple to characterise the behaviour of these

408 pollinators: being constrained to forage on a particular species of plant does not mean

409 that movement needs to be constrained to the areas in which those plants grow. Our

410 movement rules therefore need to consider whether managed features of the landscape

411 have similar effects in different species. For example, hedgerows have many differing

412 physical and ecological effects on the agricultural landscape (Forman \& Baudry,

413 1984). Although they are relatively undisturbed relative to the surrounding landscape

414 (therefore potentially acting as wild refuge zones), they can also act as physical

415 barriers to dispersal (Joyce, Holland \& Doncaster, 1999; Wratten et al., 2003). 
416 Furthermore, if landscape structures are known to impede the movement of

417 pollinators, we still need to be careful to ensure that a barrier is not labelled as

418 impassable without good experimental evidence (Zurbuchen et al., 2010).

420 In the model, I characterise the environment as being composed of two environment

421 types: agricultural crop, and wild flowers, and assume the pollinator is switching

422 between the two, partially influenced by learned preferences and neophobia (Rands \&

423 Whitney, 2010; 2011). Different floral species may be more or less attractive

424 depending upon their spatial distribution and proximity (Nattero et al., 2011;

425 Hanoteaux, Tielbörger \& Seifan, 2013), and creating a spatially realistic model that

426 accounts for the distribution of multiple forage types may require us to understand all

427 the switches in preference that could occur when a pollinator is able to move from one

428 forage type to another. This may in turn require a lot of careful experimentation

429 considering all possible preference switches: it is unlikely we can make simple

430 predictions without doing this given the vast number of floral factors that affect

431 pollinator preference behaviour (Glover, 2007; Willmer, 2011), or at least

432 understanding better the choice rules that individual pollinators are using. Integrating

433 our understanding of how pollinators are influenced at the local scale with our

434 understanding of their landscape-scale movement is still a greatly unexplored question

435 (Mayer et al., 2011), and there is much scope for combining methodologies such as

436 that presented here with field and laboratory experiments. Similarly, models should

437 also take account of the effects of pollinators on floral resources at the local scale, as

438 this interaction has implications for community ecology and biodiversity (Jeltsch et

439 al., 2013; Qu et al., 2013). 


\section{CONCLUSIONS}

443

444 The effects of habitat loss and fragmentation can be explored using a simple spatially-

445 explicit individual-based modelling framework that combines sensible behavioural

446 rules and suitable landscape information: however, suitable rules need to be

447 identified. The approach linking behavioural ecology and landscape ecology that was

448 envisioned by Lima \& Zollner (1996) is still relatively unexplored, and we still need

449 to see stronger links between models of movement and landscape ecology, with the

450 results of these models being fed back into experimental manipulations. Ultimately,

451 these can be used to inform conservation strategies (Knowlton \& Graham, 2010) and

452 aid our management of the vital pollination services provided by the animals living at

453 the hearts of our agricultural landscapes. 
458

459

460

461

462

463

464

465

466

467

468

469

470

471

472

473

474

475

476

477

478

479

480

481

482

483

484

485

486

487

488

489

490

491

492

493

494

495

496

497

498

499

500

501

502
Batáry P, Báldi A, Kleijn D, Tscharntke T. 2011. Landscape-moderated biodiversity effects of agri-environmental management: a meta-analysis. Proceedings of the Royal Society B 278:1894-1902. 10.1098/rspb.2010.1923

Bates D, Maechler M, Bolker B. 2012. Package 'Ime4': linear mixed-effects models using S4 classes. [available at http://lme4.r-forge.r-project.org/ ] .

Baum KA, Haynes KF, Dillemuth FP, Cronin JT. 2004. The matrix enhances the effectiveness of corridors and stepping stones. Ecology 85:2671-2676. 10.1890/040500

Beier P, Noss RF. 2008. Do habitat corridors provide connectivity? Conservation Biology 12:1241-1252. 10.1111/j.1523-1739.1998.98036.x

Bélisle M. 2005. Measuring landscape connectivity: the challenge of behavioral landscape ecology. Ecology 86:1988-1995. 10.1890/04-0923

Biesmeijer JC, Roberts SPM, Reemer M, Ohlemüller R, Edwards M, Peeters T, Schaffers AP, Potts SG, Kleukers R, Thomas CD, Settele J, Kunin WE. 2006. Parallel declines in pollinators and insect-pollinated plants in Britain and the Netherlands. Science 313:351-354.

Brown MJF, Paxton RJ. 2009. The conservation of bees: a global perspective. Apidologie 40:410-416. 10.1051/apido/2009019

Carvalheiro LG, Veldtman R, Shenkute AG, Tesfay GB, Pirk CWW, Donaldson JS, Nicolson SW. 2011. Natural and within-farmland biodiversity enhances crop productivity. Ecology Letters 14:251-259. 10.1111/j.1461-0248.2010.01579.x

Charlton NL, Houston AI. 2010. What currency do bumble bees maximize? PLoS One 5:e12186. 10.1371/journal.pone.0012186

Collinge SK. 2000. Effects of grassland fragmentation on insect species loss, colonization, and movement patterns. Ecology 81:2211-2226. 10.1890/00129658(2000)081[2211:EOGFOI]2.0.CO;2

Davies ZG, Pullin AS. 2007. Are hedgerows effective corridors between fragments of woodland habitat? An evidence-based approach. Landscape Ecology 22:333-351. 10.1007/s10980-006-9064-4

Ernoult A, Vialatte A, Butet A, Michel N, Rantier Y, Jambon O, Burel F. in press. Grassy strips in their landscape context, their role as new habitat for biodiversity. Agriculture, Ecosystems and Environment. 10.1016/j.agee.2012.07.004

Fischer J, Lindenmayer DB. 2007. Landscape modification and habitat fragmentation: a synthesis. Global Ecology and Biogeography 16:265-280.

Forester JD, Im HK, Rathouz PJ. 2009. Accounting for animal movement in estimation of resource selection functions: sampling and data analysis. Ecology 90:3554-3565. 10.1890/08-0874.1

Forman RTT, Baudry J. 1984. Hedgerows and hedgerow networks in landscape ecology. Environmental Management 8:495-510. 10.1007/BF01871575

Fried JH, Levey DJ, Hogsette JA. 2005. Habitat corridors function as both drift fences and movement conduits for dispersing flies. Oecologia 143:645-651. 10.1007/s00442-005-0023-6

Gallai N, Salles J-M, Settele J, Vaissière BE. 2009. Economic valuation of the vulnerability of world agriculture confronted with pollinator decline. Ecological Economics 68:810-821. 10.1016/j.ecolecon.2008.06.014 
Garibaldi LA, Steffan-Dewenter I, Winfree R, Aizen MA, Bommarco R, Cunningham SA, Kremen C, Carvalheiro LG, Harder LD, Afik O, Bartomeus I, Benjamin F, Boreux V, Cariveau D, Chacoff NP, Dudenhöffer JH, Freitas BM, Ghazoul J, Greenleaf S, Hipólito J, Holzschuh A, Howlett B, Isaacs R, Javorek SK, Kennedy CM, Krewenka KM, Krishnan S, Mandelik Y, Mayfield MM, Motzke I, Munyuli T, Nault BA, Otieno M, Petersen J, Pisanty G, Potts SG, Rader R, Ricketts TH, Rundlöf M, Seymour CL, Schüepp C, Szentgyörgyi H, Taki H, Tscharntke T, Vergara CH, Viana BF, Wanger TC, Westphal C, Williams N, Klein AM. 2013. Wild pollinators enhance fruit set of crops regardless of honey bee abundance. Science 339:1608-1611. 10.1126/science. 1230200

Getz WM, Saltz D. 2008. A framework for generating and analyzing movement paths on ecological landscapes. Proceedings of the National Academy of Sciences of the USA 105:19066-19071. 10.1073/pnas.0801732105

Glover BJ. 2007. Understanding flowers and flowering - an integrated approach. Oxford: Oxford University Press.

Goulson D, Lye GC, Darvill B. 2008. Decline and conservation of bumble bees. Annual Review of Entomology 53:191-208. 10.1146/annurev.ento.53.103106.093454

Hadley AS, Betts MG. 2012. The effects of landscape fragmentation on pollination dynamics: absence of evidence not evidence of absence. Biological Reviews 87:526-544. 10.1111/j.1469-185X.2011.00205.x

Hamby DM. 1994. A review of techniques for parameter sensitivity analysis of environmental models. Environmental Monitoring and Assessment 32:135-154.

Hanoteaux S, Tielbörger K, Seifan M. 2013. Effects of spatial patterns on the pollination success of a less attractive species. Oikos 122:867-880. 10.1111/j.16000706.2012.20801.x

Henry M, Fröchen M, Maillet-Mezeray J, Breyne E, Allier F, Odoux J-F, Decourtye A. 2012. Spatial autocorrelation in honeybee foraging activity reveals optimal focus scale for predicting agro-environmental scheme efficiency. Ecological Modelling 225:103-114. 10.1016/j.ecolmodel.2011.11.015

Holzschuh A, Dudenhöffer J-H, Tscharntke T. 2012. Landscapes with wild bee habitats enhance pollination, fruit set and yield of sweet cherry. Biological Conservation 153:101-107. 10.1016/j.biocon.2012.04.032

Hothorn T, Bretz F, Westfal P. 2012. multcomp: simultaneous inference in general parametric models [available at http://cran.rproject.org/web/packages/multcomp/index.html ].

Houston AI, McNamara JM. 1999. Models of adaptive behaviour: an approach based on state. Cambridge: Cambridge University Press.

Jeltsch F, Bonte D, Pe'er G, Reineking B, Leimgruber P, Balkenhol N, Schröder B, Buchmann CM, Mueller T, Blaum N, Zurell D, Böhning-Gaese K, Wiegand T, Eccard JA, Hofer H, Reeg J, Eggers U, Bauer S. 2013. Integrating movement ecology with biodiversity research - exploring new avenues to address spatiotemporal biodiversity dynamics. Movement Ecology 1:6. 10.1186/20513933-1-6

Jenerette GD, Shen W. 2012. Experimental landscape ecology. Landscape Ecology 9:1237-1248. 10.1007/s10980-012-9797-1

Joyce KA, Holland JM, Doncaster CP. 1999. Influences of hedgerow intersections and gaps on the movement of carabid beetles. Bulletin of Entomological Research 89:523-531. 10.1017/S000748539900067X 
552

553

554

555

556

557

558

559

560

561

562

563

564

565

566

567

568

569

570

571

572

573

574

575

576

577

578

579

580

581

582

583

584

585

586

587

588

589

590

591

592

593

594

595

596

597

598

599

600

601
Knowlton JL, Graham CH. 2010. Using behavioral landscape ecology to predict species' responses to land-use and climate change. Biological Conservation 143:1342-1354. 10.1016/j.biocon.2010.03.011

Lihoreau M, Chittka L, Le Comber SC, Raine NE. 2012. Bees do not use nearestneighbour rules for optimization of multi-location routes. Biology Letters 8:13-16. 10.1098/rsbl.2011.0661

Lima SL, Zollner PA. 1996. Towards a behavioral ecology of ecological landscapes. Trends in Ecology and Evolution 11:131-135. 10.1016/0169-5347(96)81094-9

Lonsdorf E, Kremen C, Ricketts T, Winfree R, Williams N, Greenleaf S. 2009. Modelling pollination services across agricultural landscapes. Annals of Botany 103:1859-1600. 10.1093/aob/mcp069

Martin J, van Moorter B, Revilla E, Blanchard P, Dray S, Quenette P-Y, Allainé D, Swenson JE. 2013. Reciprocal modulation of internal and external factors determines individual movements. Journal of Animal Ecology 82:290-300. 10.1111/j.1365-2656.2012.02038.x

Matsumoto M, Nishimura T. 1998. Mersenne Twister: a 623-dimensionally equidistributed uniform pseudo-random number generator. ACM Transactions on Modeling and Computer Simulation 8:3-30.

Mayer C, Adler L, Armbruster WS, Dafni A, Eardley C, Huang S-Q, Kevan PG, Ollerton J, Packer L, Ssymank A, Stout JC, Potts SG. 2011. Pollination ecology in the 21st Century: key questions for future research. Journal of Pollination Ecology $3: 8-23$.

McLane AJ, Semeniuk C, McDermid GJ, Marceau DJ. 2011. The role of agent-based models in wildlife ecology and management. Ecological Modelling 222:15441556. 10.1016/j.ecolmodel.2011.01.020

McNamara JM, Houston AI. 2009. Integrating function and mechanism. Trends in Ecology and Evolution 24:670-675. 10.1016/j.tree.2009.05.011

Morandin LA, Winston ML. 2006. Pollinators provide economic incentive to preserve natural land in agroecosystems. Agriculture, Ecosystems and Environment 116:289-292. 10.1016/j.agee.2006.02.012

Morrell LJ, Ruxton GD, James R. 2011. The temporal selfish herd: predation risk while aggregations form. Proceedings of the Royal Society B 278:605-612. 10.1098/rspb.2010.1605

Nathan R, Getz WM, Revilla E, Holyoak M, Kadmon R, Saltz D, Smouse PE. 2008. A movement ecology paradigm for unifying organismal movement research. Proceedings of the National Academy of Sciences of the USA 105:19052-19059. 10.1073/pnas.0800375105

Nattero J, Malerba R, Medel R, Cocucci A. 2011. Factors affecting pollinator movement and plant fitness in a specialized pollination system. Plant Systematics and Evolution 296:77-85. 10.1007/s00606-011-0477-4

Norfolk O, Sadiki LL, Broughton B, Otleno M, Nuttman C. 2013. Tea breaks: how flower visitors can benefit from unplanned floral buffer strips in a Tanzanian tea plantation. African Journal of Ecology 51:380-384. 10.1111/aje.12039

Öckinger E, Smith HG. 2008. Do corridors promote dispersal in grassland butterflies and other insects? Landscape Ecology 23:27-40. 10.1007/s10980-007-9167-6

Ohashi K, Thomson JD. 2009. Trapline foraging by pollinators: its ontogeny, economics and possible consequences for plants. Annals of Botany 103:1365-1378.

Orłowski G. 2010. Effect of boundary vegetation and landscape features on diversity and abundance of breeding bird communities of abandoned crop fields in southwest Poland. Bird Study 57:175-182. 10.1080/00063650903449946 
602

603

604

605

606

607

608

609

610

611

612

613

614

615

616

617

618

619

620

621

622

623

624

625

626

627

628

629

630

631

632

633

634

635

636

637

638

639

640

641

642

643

644

645

646

647

648

649
Orrock JL, Curler GR, Danielson BJ, Coyle DR. 2011. Large-scale experimental landscapes reveal distinctive effects of patch shape and connectivity on arthropod communities. Landscape Ecology 26:1361-1372. 10.1007/s10980-011-9656-5

Potts SG, Biesmeijer JC, Kremen C, Neumann P, Schweiger O, Kunin WE. 2010. Global pollinator declines: trends, impacts and drivers. Trends in Ecology and Evolution 25:345-353. 10.1016/j.tree.2010.01.007

Procheș Ş, Wilson JRU, Veldtman R, Kalwij JM, Richardson DM, Chown SL. 2005. Landscape corridors: possible dangers? Science 310:779-783. 10.1126/science.310.5749.779

Qu H, Seifan T, Tielbörger K, Seifan M. 2013. A spatially explicit agent-based simulation platform for investigating effects of shared pollination service on ecological communities. Simulation Modelling Practice and Theory 37:107-124. 10.1016/j.simpat.2013.06.003

R Development Core Team. 2012. $R$ : a language and environment for statistical computing. Vienna: R Foundation for Statistical Computing.

Rands SA. 2011. Approximating optimal behavioural strategies down to rules-ofthumb: energy reserve changes in pairs of social foragers. PLoS One 6:e22104. 10.1371/journal.pone.0022104

Rands SA. 2012. Mobbing and sitting tight at the nest as methods of avoiding brood parasites. Interface Focus 2:217-225. 10.1098/rsfs.2011.0080

Rands SA, Pettifor RA, Rowcliffe JM, Cowlishaw G. 2004. State-dependent foraging rules for social animals in selfish herds. Proceedings of the Royal Society $B$ 271:2613-2620. 10.1098/rspb.2004.2906

Rands SA, Pettifor RA, Rowcliffe JM, Cowlishaw G. 2006. Social foraging and dominance relationships: the effects of socially mediated interference. Behavioral Ecology and Sociobiology 60:572-581. 10.1007/s00265-006-0202-4

Rands SA, Whitney HM. 2008. Floral temperature and optimal foraging: is heat a feasible floral reward for pollinators? PLoS One 3:e2007. 10.1371/journal.pone.0002007

Rands SA, Whitney HM. 2010. Effects of pollinator density-dependent preferences on field margin pollination in the midst of agricultural monocultures: a modelling approach. Ecological Modelling 221:1310-1316. 10.1016/j.ecolmodel.2010.01.014

Rands SA, Whitney HM. 2011. Field margins, foraging distances and their impacts on nesting pollinator success. PLoS One 6:e25971. 10.1371/journal.pone.0025971

Reynolds AM, Lihoreau M, Chittka L. 2013. A simple iterative model accurately captures complex trapline formation by bumblebees across spatial scales and flower arrangements. PLoS Computational Biology 9:e1002938. 10.1371/journal.pcbi.1002938

Schick RS, Loarie SR, Colchero F, Best BD, Boustany A, Conde DA, Halppin PN, Joppa LN, McClellan CM, Clark JS. 2008. Understanding movement data and movement processes: current and emerging directions. Ecology Letters 11:13381350. 10.1111/j.1461-0248.2008.01249.x

van Buskirk J, Willi Y. 2004. Enhancement of farmland biodiversity within set-aside land. Conservation Biology 18:987-994. 10.1111/j.1523-1739.2004.00359.x

Willmer P. 2011. Pollination and floral ecology. Princeton: Princeton University Press.

Winfree R. 2010. The conservation and restoration of wild bees. Annals of the New York Academy of Sciences 1195:169-197. 10.1111/j.1749-6632.2010.05449.x 
650 Winfree R, Williams NM, Dushoff J, Kremen C. 2007. Native bees provide insurance 651 against ongoing honey bee losses. Ecology Letters 10:1105-1113. 10.1111/j.1461$652 \quad 0248.2007 .01110 . x$

653

654

655

656

657

658

659

660

661

662

663

Wratten SD, Bowie MH, Hickman JM, Evans AM, Sedcole JR, Tylianakis JM. 2003. Field boundaries as barriers to movement of hover flies (Diptera: Syrphidae) in cultivated land. Oecologia 134:605-611. 10.1007/s00442-002-1128-9

Yaacobi G, Ziv Y, Rosenzweig ML. 2007. Effects of interactive scale-dependent variables on beetle diversity patterns in a semi-arid agricultural landscape. Landscape Ecology 22:687-703. 10.1007/s10980-006-9061-7

Zurbuchen A, Bachofen C, Müller A, Hein S, Dorn S. 2010. Are landscape structures insurmountable barriers for foraging bees? A mark-recapture study with two solitary pollen specialist species. Apidologie 41:497-508. 10.1051/apido/2009084

Zurbuchen A, Landert L, Klaiber J, Müller A, Hein S, Dorn S. 2009. Maximum foraging ranges in solitary bees: only a few individuals have the capability to cover

664

665 long foraging distances. Biological Conservation 143:669-676.

666

667 10.1016/j.biocon.2009.12.003

668 
671 Supplemental Information 1. Zipped file containing example C++ code for the

\section{SUPPLEMENTAL INFORMATION}

model. Three text files are contained, with a detailed explanation for them described in the header of 'main.cpp'.

Supplemental Information 2. Results of sensitivity analysis for the combined effects of $p_{F}$ and number of set-aside fields on the mean and standard deviation of: $(a, b)$ the maximum metric distance travelled from the nest; $(c, d)$ the number of switches between habitat types conducted by the pollinator; and $(e, f)$ the proportion of time the pollinator spends in the wild habitat type. The line colour indicates the value of $p_{F}$, as detailed in the inset legend.

Supplemental Information 3. Results of sensitivity analysis for the combined effects of $p_{S}$ and number of set-aside fields. See legend to Supplemental Information 2 for details. The line colour indicates the value of $p_{S}$, as detailed in the inset legend.

Supplemental Information 4. Results of sensitivity analysis for the combined effects of $r$ and number of set-aside fields. See legend to Supplemental Information 2 for details. The line colour indicates the value of $r$, as detailed in the inset legend.

694 
695 Supplemental Information 6. Results of sensitivity analysis for the combined effects

696 of $p_{F}$ and hedgerow removal. See legend to Supplemental Information 2 for details.

697 The line colour indicates the value of $p_{F}$, as detailed in the inset legend.

698

699 Supplemental Information 7. Results of sensitivity analysis for the combined effects

700 of $p_{S}$ and hedgerow removal. See legend to Supplemental Information 2 for details.

701 The line colour indicates the value of $p_{S}$, as detailed in the inset legend.

702

703 Supplemental Information 8. Results of sensitivity analysis for the combined effects

704 of $r$ and hedgerow removal. See legend to Supplemental Information 2 for details.

705 The line colour indicates the value of $r$, as detailed in the inset legend.

706

707 Supplemental Information 9. Results of sensitivity analysis for the combined effects

708 of number of fields initially seeded in the landscape and hedgerow removal. See

709 legend to Supplemental Information 2 for details. The line colour indicates the value

710 of number of fields initially seeded, as detailed in the inset legend.

711

712 Supplemental Information 10. Full post-hoc test results for the results described in

713 Table 1. 


\section{Table 1 (on next page)}

Overall changes in mean summary statistics of pollinator movement for the different models.

$\Uparrow \Uparrow / \Downarrow \Downarrow$ : strong increase/decrease across the range of the parameter changed, with most post-hoc comparisons significant (see Supplemental Information 10); $\Uparrow / \Downarrow$ : moderate increase/decrease across the range of the parameter changed, with some post-hoc comparisons significant; $(\Downarrow)$ : significant decrease in response to parameter being changed only significant at one extreme end of range considered; - : no obvious pattern in response to parameter being changed, regardless of significance (or lack of significance) in post-hoc comparisons. Statistics reported are for likelihood ratio tests. 


\begin{tabular}{|c|c|c|c|c|c|c|}
\hline & \multicolumn{2}{|c|}{ maximum distance from nest } & \multicolumn{2}{|c|}{ number of habitat changes } & \multicolumn{2}{|c|}{ proportion of time spent in wild habitat } \\
\hline Model 1: increasing $p_{F}$ & $\Uparrow \Uparrow$ & $\chi_{5}^{2}=4768.9, p<0.001$ & - & $\chi_{5}^{2}=14.4, p=0.013$ & $\Downarrow$ & $\chi_{5}^{2}=91.1, p<0.001$ \\
\hline Model 2: decreasing $r$ & $\Uparrow \Uparrow$ & $\chi_{13}^{2}=542.2, p<0.001$ & $\Uparrow \Uparrow$ & $\chi_{5}^{2}=10446.0, p<0.001$ & $\Downarrow \Downarrow$ & $\chi_{13}^{2}=4213.7, p<0.001$ \\
\hline Model 3: increasing set-aside nuigber & $(\Downarrow)$ & $\chi_{10}^{2}=71.5, p<0.001$ & $\Downarrow \Downarrow$ & $\chi_{10}^{2}=1225.0, p<0.001$ & $\Uparrow \Uparrow$ & $\chi_{10}^{2}=3154.0, p<0.001$ \\
\hline $\begin{array}{l}\text { Model 3a: increasing set-aside nim ber with no } \\
\text { movement into cultivated fields on }\end{array}$ & $\Uparrow \Uparrow$ & $\chi_{10}^{2}=1146.8, p<0.001$ & & & & \\
\hline Model 4: increasing number of hedgerows removed & - & $\chi_{10}^{2}=56.5, p<0.001$ & $\Downarrow$ & $\chi_{10}^{2}=90.5, p<0.001$ & $(\Downarrow)$ & $\chi_{10}^{2}=52.5, p<0.001$ \\
\hline $\begin{array}{l}\text { Model 4a: increasing number of hedgerows removed } \\
\text { with no movement into cultivated fields }\end{array}$ & - & $\chi_{10}^{2}=22.2, p=0.014$ & & & & \\
\hline
\end{tabular}




\section{Figure 1}

Illustration of how set-asides were added into the landscape.

The left hand panel shows a $101 \times 101$ cell landscape generated using 30 randomly placed field seeds, where white cells represent agricultural crops and black cells represent wild land or hedgerows. Set-aside fields are added by randomly selecting fields containing agricultural crops, and resetting the cells within the field as wild land. Moving from left to right, each successive panel has two additional agricultural fields redesignated as set-aside. Note that this is a simplified sketch: the results described consider a larger landscape and add more than two fields at each assay point.

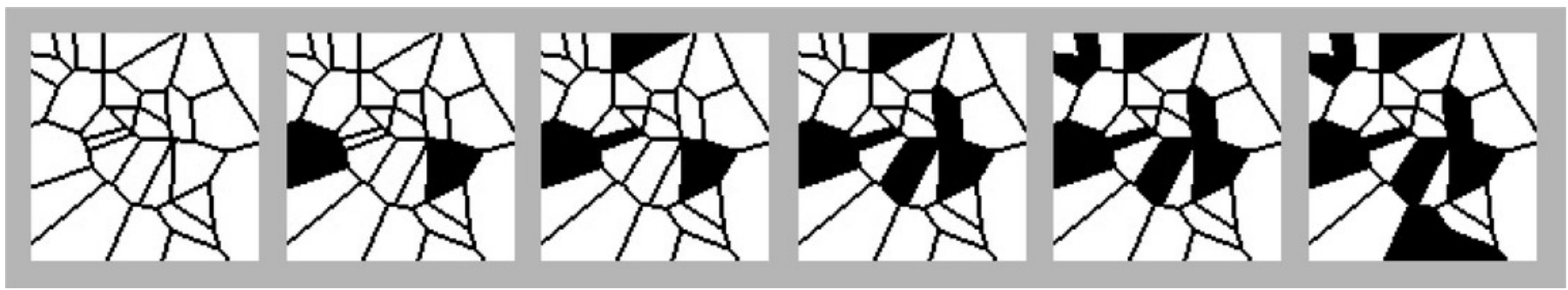




\section{Figure 2}

Illustration of how hedgerows were removed from the landscape.

The left hand panel shows a $101 \times 101$ cell landscape generated using 30 randomly placed field seeds, where white cells represent agricultural crops and black cells represent wild land or hedgerows. Hedgerows are removed by randomly selecting adjacent fields, and removing the cells between them that were initially designated as hedgerows. Moving from left to right, each successive panel has four additional hedgerows removed.

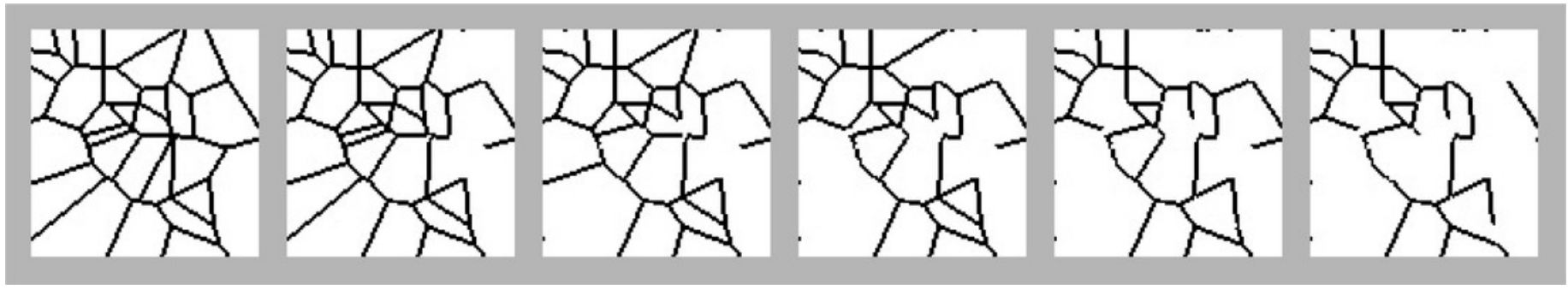




\section{Figure 3}

Box plots showing trends for Model 1.

Box plots show the effects of changing the probability of moving forwards in a period $\left(p_{F}\right)$ on the median value of: a) maximum distance travelled away from the nest in 1000 movements; $b$ ) the number of times the forager changes habitat; and $c$ ) the proportion of time the forager spends in the 'wild' habitat. 

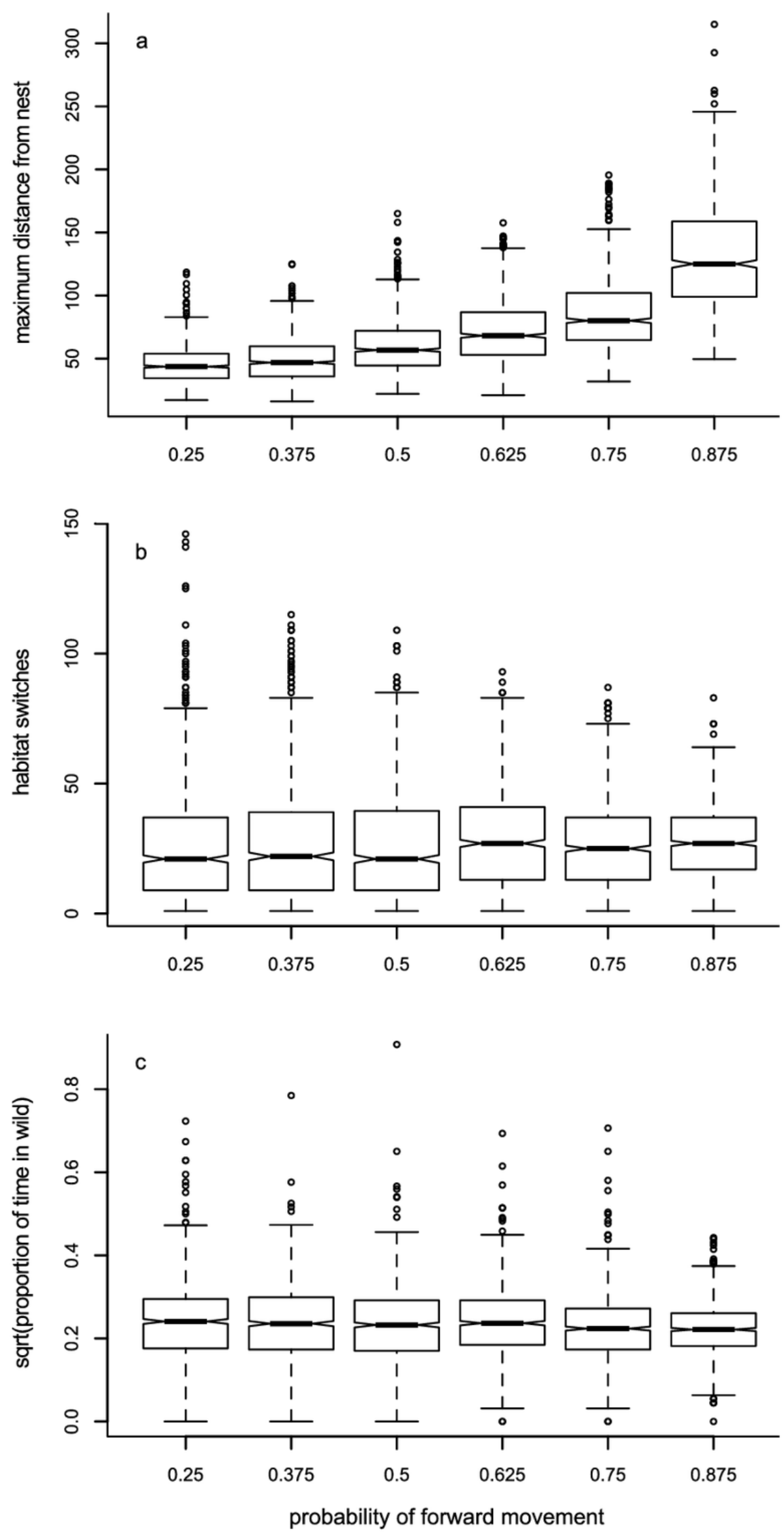


\section{Figure 4}

Box plots showing trends for Model 2.

Box plots show the effects of changing the probability of switching foraging habitat during a period ( $r$ ) on the median value of: a) maximum distance travelled away from the nest in 1000 movements; $b$ ) the number of times the forager changes habitat; and $c$ ) the proportion of time the forager spends in the 'wild' habitat. 

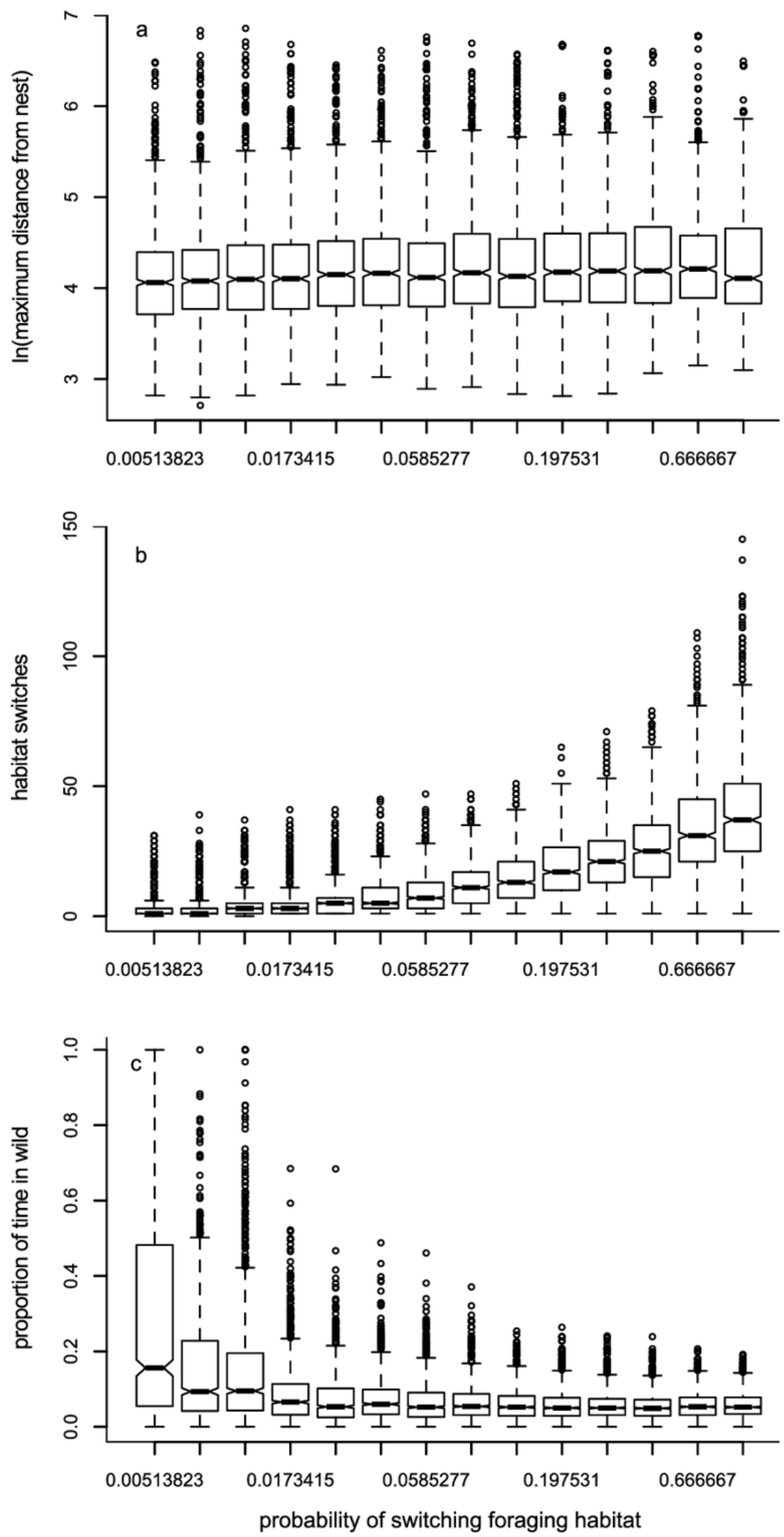


\section{Figure 5}

Box plots showing trends for Models 3 (panels $a-c$ ) and 3a (panel $d$ ).

Box plots show the effects of changing the number of set-aside fields in the foraging environment on the median value of: a) maximum distance travelled away from the nest in 1000 movements; $b$ ) the number of times the forager changes habitat; $c$ ) the proportion of time the forager spends in the 'wild' habitat; and d) the maximum distance travelled away from the nest when the forager never crosses into the 'non-wild' habitat.
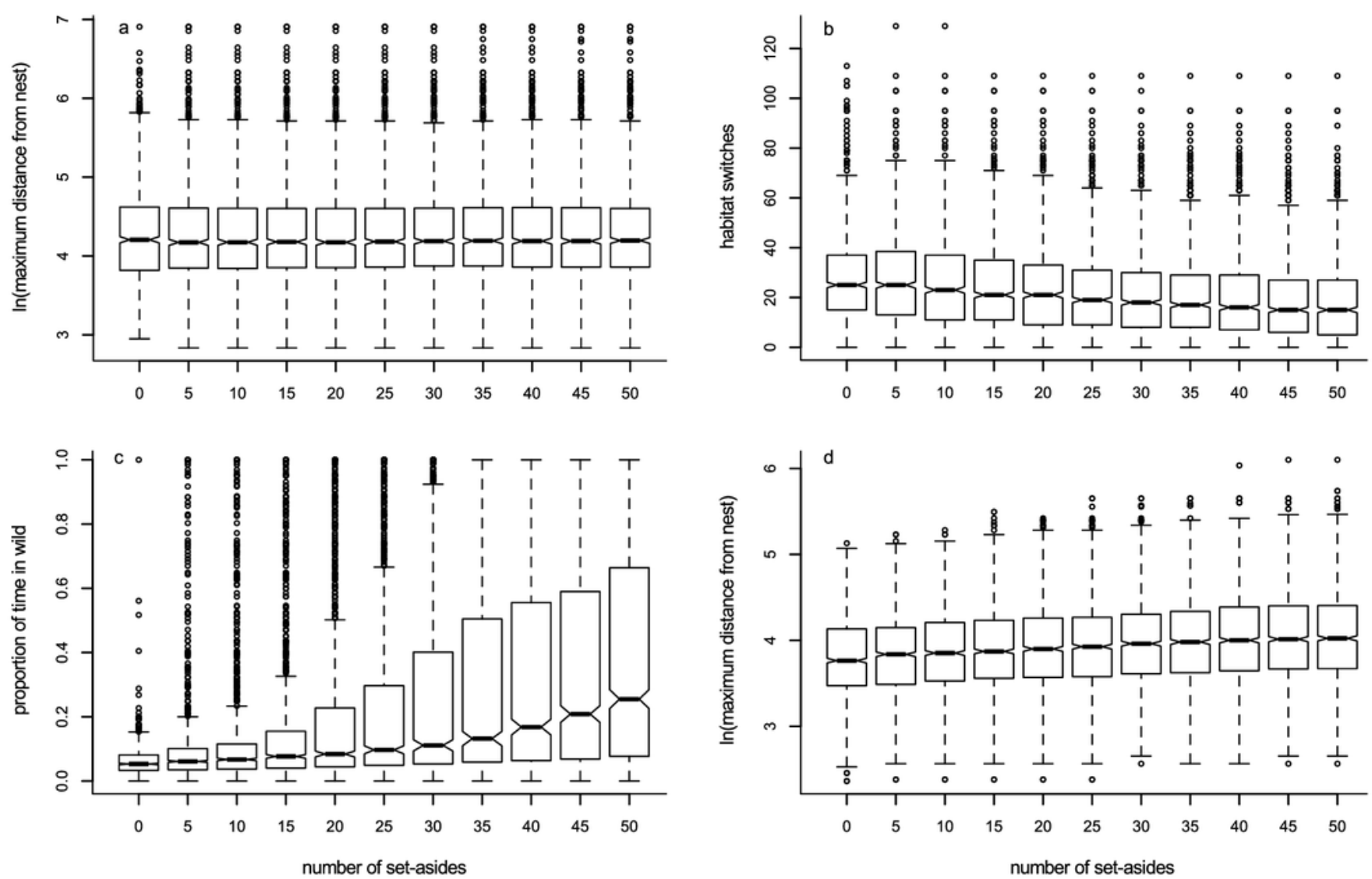


\section{Figure 6}

Box plots showing trends for Models 4 (panels a-c) and 4a (panel $d$ ).

Box plots show the effects of changing the number of hedgerows removed from the foraging environment on the median value of: a) maximum distance travelled away from the nest in 1000 movements; $b$ ) the number of times the forager changes habitat; $c$ ) the proportion of time the forager spends in the 'wild' habitat; and $d$ ) the maximum distance travelled away from the nest when the forager never crosses into the 'non-wild' habitat.
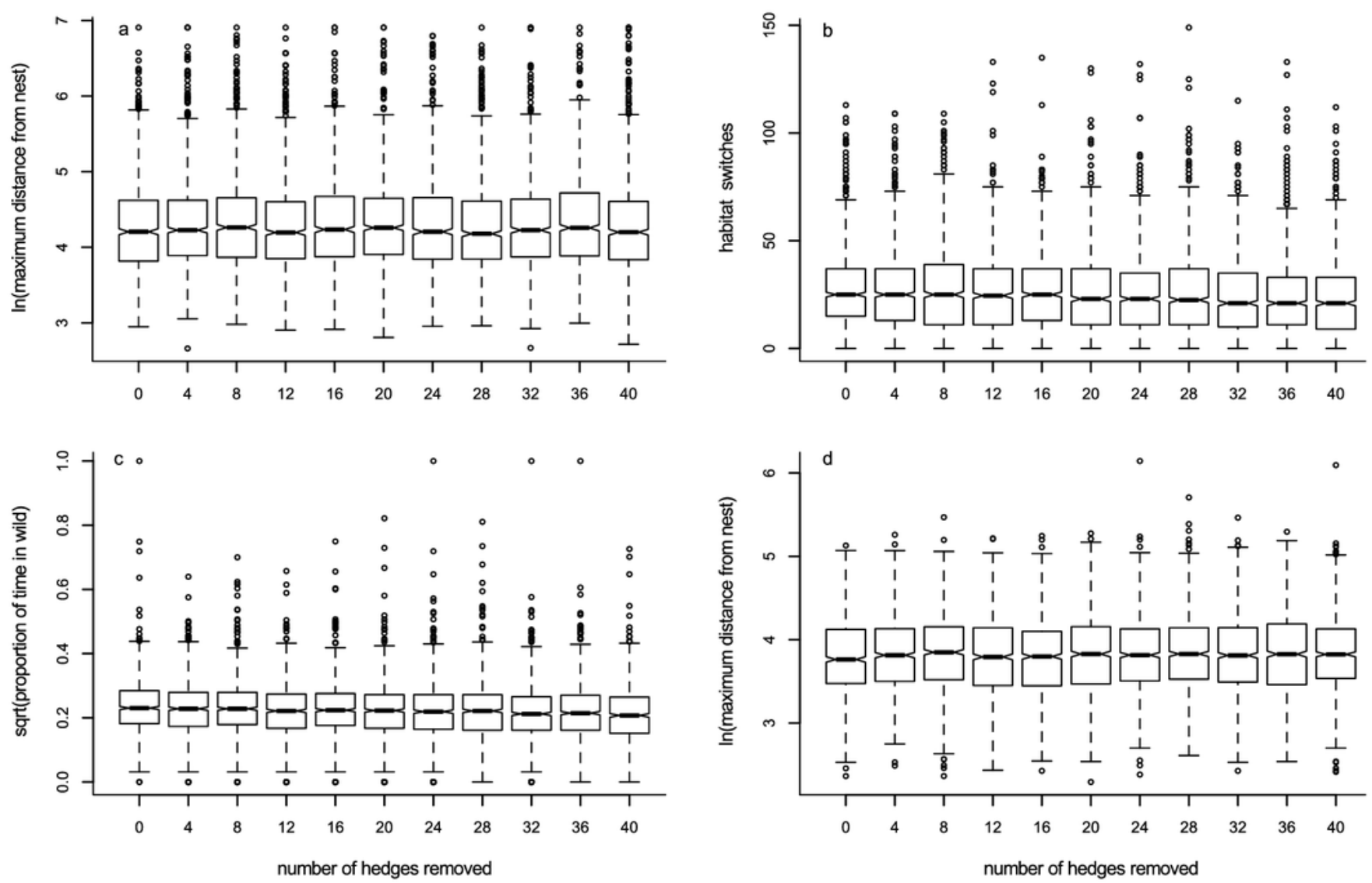